\title{
As Representações Sociais da Depressão Pós-parto Elaboradas por Mães Puérperas
}

Social representations of postpartum depression elaborated by postnatal mothers

Maria da Penha de Lima Coutinho \& Evelyn Rúbia de Albuquerque Saraiva

Universidade Federal da Paraíba

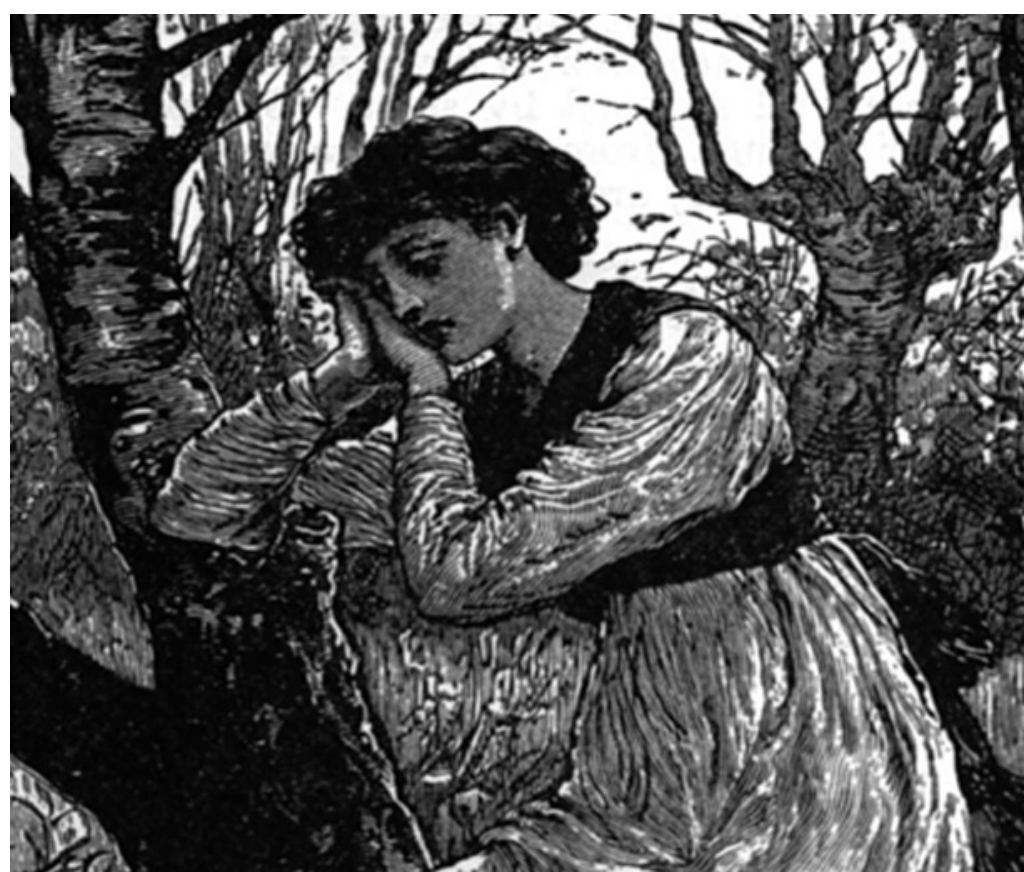


Resumo: O estudo psicossociológico versou sobre a depressão pós-parto desde a experiência subjetiva das mães no contexto puerperal até as comunicações veiculadas no seu grupo de pertencimento. Buscou-se apreender as representações sociais da depressão e da experiência materna elaboradas pelas puérperas com e sem sintomatologia depressiva. Trata-se de uma pesquisa descritiva, com mães usuárias de um serviço público de saúde, que foram divididas em dois grupos, com base na pontuação obtida pela escala de Edinburgh para rastreamento da depressão pós-parto: trinta e duas puérperas portadoras de sintomatologia de depressão e trinta e três participantes que não apresentavam essa sintomatologia. Foram utilizados a associação livre de palavras, analisada pelo software Tri-Deux-Mot, e um questionário sociodemográfico, tratado pelo SPSS. Para o estímulo indutor depressão, nas puérperas sem sintomatologia, emergiram manifestações psico-orgânicas, valorativas e histórico-factuais. As mães depressivas ancoraram a depressão em elementos psico-afetivos, que trouxeram repercussões para o seu relacionamento com os bebês. Constatou-se a necessidade da utilização de procedimentos plurimetodológicos.

Palavras-chave: Representação social. Depressão pós-parto. Puerpério. Escala de Depressão Pós-Parto de Edinburg.

\begin{abstract}
The psychosociologic study approached the postpartum depression on the subjective experience of the mothers in the postnatal context taking into account the information vehiculated in their belonging group. The study aimed at the apprehension of the social representations of depression and of maternal experience elaborated by postnatal mothers with or without depressive symptomatology. A descriptive research with mothers, users of a public health service, was made and two groups were formed, based on the pontuation obtained by the Edinburgh scale for tracking the postpartum depression: 32 postnatal mothers with depression symptomatology and 33 participants that didn't have this symptomatology. The free association of words was used, and an analysis by the Tri-Deux-Mot software and a social-demographic questionaire were made and treated by the SPSS. For the inductor stimulus depression, on the postnatal without symptomatology, psycho-organic, valourative and historical-factual manifestations emerged. The depressive mothers anchorated the depression in psycho-afective factors, pointing out repercussions on their relationship with the babies. The study pointed out the need to use plural methodological procedures.
\end{abstract}

Keywords: Social representation. Postpartum. Depression postnatal. Edinburgh Postnatal Depression Scale.

\title{
As representações sociais da depressão pós-parto elaboradas por mães puérperas depressão pós-parto: Um estudo psicossociológico
}

A depressão, enquanto sofrimento psíquico, nem sempre expressa um estado patológico, pois encontra origem na própria existência humana, na sua inquietação diante da condição de ser temporal, finito e incompleto. O sofrimento e a dor são sentimentos subjetivos manifestados tanto na esfera afetiva, na dor mental, como na esfera física, nas condições fisiológicas em geral. Concebido como manifestação psicossocial, o sofrimento psíquico expressa um tipo de doença ou síndrome situada entre a subjetividade e a 
Como malestar moderno amplamente identificado nos indivíduos humanos, a depressão é concebida, por um lado, como um fenômeno biológico e, por outro, como saída inevitável do homem diante dos limites que a civilização moderna the impõe. realidade exterior, sendo a expressão de diferentes formas de experiência de malestar, de sentimentos reunidos nas condições de exclusão e solidão (Nóbrega, Fontes, \& Paula, 2005).

Como mal-estar moderno amplamente identificado nos indivíduos humanos, a depressão é concebida, por um lado, como um fenômeno biológico e, por outro, como saída inevitável do homem diante dos limites que a civilização moderna Ihe impõe. Essa limitação sustenta-se no esvaziamento do ser humano como tal, transformado em um número do registro social (Bolguese, 2004).

No entanto, apesar de a literatura referirse a esse amplo alcance da ocorrência de transtornos depressivos na população mundial, as mulheres se destacam como um segmento mais sensível do que os homens na manifestação da depressão. As mulheres têm merecido a atenção dos estudos sobre depressão principalmente nos contextos que envolvem exclusivamente o mundo feminino, notadamente nas situações relativas à maternidade (Lara, Acevedo, \& Berenzon, 2004).

O nascimento de um bebê tem sido associado a situações de estresse em algumas famílias, diante das mudanças nas rotinas diárias ocorridas desde o período gravídico, por ocasião do parto e na fase do puerpério. A depressão materna registrada após o nascimento de um bebê, segundo Frizzo e Piccinini (2005), é um motivo de preocupação tanto para a mãe e para a criança como também para a família, visto que configura um momento oportuno para o aparecimento de problemas emocionais nas mães, destacandose os transtornos psico-afetivos.
Na literatura consultada, observou-se uma incidência de depressão pós-parto de 10\% a $42 \%$ das mães puérperas, em pesquisas realizadas em todo o mundo, inclusive no Brasil. Nos Estados Unidos da América, observou-se a prevalência de 39\% (Howell, Mora, \& Leventhal, 2006) e 42,6\% (Kuo et al., 2004); no Reino Unido, entre 12 e 13\% (Howard, 2005); na Índia, a incidência de depressão puerperal ficou entre 16\% a 19,8\% (Chandran, Tharyan, Muliyil, \& Abraham, 2002); na Turquia, 27,2\% (Inandi et al., 2002); na Austrália, entre 10 a 15\% (Boyce et al., 2000); 18\% nos Emirados Árabes (Abou-Seleh \& Ghubash, 1997), e, na Espanha, 7\% (Sierra Manzano, Carro García, \& Ladrón, 2002). As pesquisas brasileiras apresentaram índices de 37,1\% (Cruz, Simões, \& Faisal-Cury, 2005), de 38\% (Da-Silva, Moraes-Santos, Carvalho, Martins, \& Teixeira, 1998), de 13,4\% (Santos, Martins, \& Pasquali, 1999) e de 13,3\% (Cantilino, Albuquerque, Cantilino, Maia, \& Sougey, 2003).

Apesar dessa incidência, a avaliação de depressão no período puerperal é difícil devido à imprecisão no diagnóstico entre as formas clínicas, subclínicas e as nãopatológicas, como têm sido abordados os transtornos psico-afetivos. Nesse contexto, o tipo de depressão a ser investigado enquadrase nas formas não-patológicas, no tipo de depressão reativa, aquela desencadeada, provavelmente, pela intercorrência de um fato relevante e novo na vida do indivíduo (Kaplan \& Sadock, 1990).

A depressão puerperal, também denominada depressão pós-parto, maternal ou pós-natal, enquanto depressão reativa e não-patológica, tem intensidade não especificada, em que o conflito desencadeante pode ser discernido 
A pessoa deprimida de forma benigna expressa sentimentos de solidão e afirma que a vida é vazia demais para continuar vivendo. com clareza e possui certa magnitude; é acompanhada de sentimentos de falta de valor próprio, de apatia ou indiferença diante dos eventos que ocorrem em seu meio ambiente. A pessoa deprimida de forma benigna expressa sentimentos de solidão e afirma que a vida é vazia demais para continuar vivendo. A auto-estima e o respeito próprio se vêem ameaçados, e os indivíduos sentem tal abatimento que encontram dificuldades de justificar sua existência (Kyes \& Hofling, 1985).

O presente estudo, além de abordar a depressão feminina, traz à tona o olhar da Psicologia social, especificamente, para o período puerperal, que, de acordo com Silva e Botti (2005), caracteriza-se por se apresentar como uma etapa de profundas alterações no âmbito social, psicológico e físico da mulher. Essa etapa da vida feminina consiste, portanto, num período instável, que demanda a necessidade de um profundo conhecimento da experiência da mulher. Tem-se observado que, além da ocorrência das involuções da genitália, são evidenciadas adaptações femininas ao período de lactação e da licença-maternidade, fases em que são observadas interações intensivas entre mães e bebês.

A ocorrência de depressão nessa fase vital da mulher alerta, também, para a importância da intervenção dos profissionais da saúde, não só no âmbito da saúde da gestante mas, em geral, no da saúde da mulher, principalmente dentro de programas voltados para a função reprodutiva aliados às ações de saúde mental.

As discussões amplas sobre a saúde da mulher, principalmente durante o ciclo gravídico-puerperal, de acordo com Moreira e Lopes (2006), pressupõem, também, uma compreensão sobre a sexualidade e a reprodução humana num contexto socioeconômico e cultural, e destacam o papel social da mulher frente às necessidades de adaptações e reajustamentos intrapsíquicos e interpessoais na mudança da identidade feminina.

As alterações humorais e psicossociais no puerpério, portanto, necessitam ser estudadas sob a ótica das configurações subjetivas da depressão pós-parto na direção da compreensão global das mulheres, distanciando-se, assim, da padronização e da patologização desse tipo de depressão (Arrais, 2005).

Para instrumentalizar a busca do conhecimento sobre a depressão pós-parto desde a experiência subjetiva das mães, no contexto da saúde feminina e das comunicações veiculadas no seu grupo de pertencimento, utilizou-se uma abordagem psicossocial, ancorada na teoria das representações sociais, de Moscovici (1978, 2003), numa tentativa de delinear as representações sociais das puérperas com e sem sintomatologia da depressão. Esse aporte teórico permite apreender a depressão puerperal como uma síndrome que afeta o físico, o humor e, em conseqüência, o pensamento, e constitui, portanto, doença que altera a maneira como a pessoa vê o mundo e sente a realidade, entende as coisas, manifesta emoções, sente a disposição e o prazer com a vida.

Para Moscovici (2003), a representação social é uma modalidade de conhecimento particular que tem por função a elaboração de comportamentos e a comunicação entre os indivíduos. As representações sociais são conjuntos simbólicos/práticos/dinâmicos cujo status é não o de uma reprodução ou reação a estímulos exteriores, mas a utilização e a 
seleção de informações a partir de repertório circulante na sociedade, destinadas à interpretação e à elaboração do real. Assim, representar um objeto, pessoa ou coisa não consiste apenas em desdobrá-lo, repeti-lo ou reproduzi-lo, mas em reconstruí-lo, retocá-lo e modificá-lo.

Jodelet (2001), uma das expoentes no estudo da representação social, define-a como "uma forma de conhecimento, socialmente elaborada e partilhada, com um objetivo prático, e que contribui para a construção de uma realidade comum a um conjunto social" (p. 22). Para essa pesquisadora, a representação social é "designada como saber de senso comum ou ainda saber ingênuo, natural, e essa forma de conhecimento é diferenciada, entre outras, do conhecimento científico" (p. 22).

De acordo com Farr (1994), o objeto representacional encontra-se inserido num ambiente ativo, reestruturado pelo indivíduo ou pelo grupo a partir da realidade social. Os atores sociais reconstroem a realidade tomando por base o sistema cognitivo do indivíduo, integrado aos seus valores, sua história, seu contexto social e ideológico.

Por considerar, portanto, a indissociabilidade entre a experiência subjetiva e a inserção social dos sujeitos, compreende-se que as representações sociais das puérperas sobre seus transtornos psico-afetivos consistem numa interpretação coletiva da realidade vivida e relatada por aquele grupo social, que direciona comportamentos e comunicações.

As representações sociais, nesta pesquisa, foram estudadas sob o ponto de vista dos seus processos sociocognitivos, que as caracterizam como saber social, com destaque para os fenômenos sociais de ordem cognitiva, e foram orientadas pelas marcas sociais e pelas condições de sua gênese (Arruda, 2002).

Para tanto, a investigação das representações sociais das puérperas, neste contexto, apoiou-se no seu conteúdo, contido num dos seus principais suportes: a linguagem. A apreensão da linguagem falada, enquanto discurso sobre a depressão e a experiência com a maternidade, possibilita abarcar o campo da representação social na totalidade das expressões, imagens e valores, entendidos como um campo estruturado de significações, saberes e informações (Arruda, 2002).

Essa abordagem do estudo das representações sociais, de acordo com Arruda (2002), é denominada de dimensional, porque apreende as "dimensões da representação no seu campo estruturado, a atitude que ela carrega e que lhe dá sua coloração afetiva, e o componente da informação que ela contém" (p. 140). Para Banchs (1998), a abordagem dimensional é também denominada de processual, genética ou dinâmica, uma vez que centra sua atenção sobre a construção da representação, da sua gênese e dos seus processos de elaboração.

Falar da representação social acerca da depressão puerperal consiste, portanto, num sistema de interpretação da realidade que dirige as relações das mães puérperas com o seu meio físico e social, segundo Farr (1994), determina seus comportamentos e suas práticas e guia, portanto, suas ações sociais.

\section{Método}

\section{Aspectos éticos e participantes}

Este estudo foi aprovado pelo Comitê de Ética do Centro de Ciências da Saúde/UFPB, conforme a Resolução CNS/MS no 196/96 (Conselho Nacional de Saúde, 1996), e 
utilizou uma amostra constituída de sessenta e cinco mães usuárias do local da pesquisa, que se encontravam acompanhadas de seus bebês, na sala de espera dos setores de pediatria e de vacinas, e que atenderam os seguintes requisitos: a) idade igual ou superior a 18 anos; b) partos ocorridos entre quinze e noventa dias antes da aplicação dos instrumentos da pesquisa, o que compreendia o puerpério tardio e remoto; c) oferecimento de leite materno como único alimento e d) cuidado do filho em tempo integral. Registrese que as mães participantes deste estudo não se encontravam presentes ao serviço público de saúde em busca de atendimento para si próprias, e sim, de consultas e vacinas para os seus bebês.

As mães pesquisadas foram divididas em dois grupos, que tomaram como referência a pontuação obtida na escala de Edinburgh (Edinburgh postpartum depression scale), instrumento de rastreamento da depressão puerperal descrito na seção seguinte. $\mathrm{O}$ primeiro grupo foi formado por trinta e duas puérperas portadoras de sintomatologia da depressão pós-parto, e o segundo grupo, por trinta e três participantes que não apresentaram sintomatologia depressiva puerperal.

Na constituição do grupo com sintomatologia da depressão pós-parto, participaram as mães que obtiveram pontuação na escala de Edinburgh igual ou maior que 11 pontos, ponto de corte estabelecido pela sua validação (Santos et al., 1999). Por sua vez, para amostra que constituiu o grupo sem sintomatologia da depressão, foram incluídas as mães que não pontuaram assim como as que obtiveram pontuação total entre 1 e 9 pontos na escala de rastreamento da depressão utilizada na investigação.

\section{Local da pesquisa e instrumentos}

O local da pesquisa foi um ambulatório materno-infantil de um serviço público de saúde localizado em João Pessoa, Paraíba, e os instrumentos aplicados foram a técnica de associação livre de palavras (TALP), o questionário sociodemográfico e a escala de Edinburgh.

A técnica de associação livre de palavras foi desenvolvida por Jung, em 1905, para uso de diagnóstico clínico, e adaptada para pesquisas no campo das representações sociais por Di Giacomo (1981). A TALP objetiva identificar as dimensões latentes dos objetos representacionais na perspectiva de uma técnica projetiva, a partir da rede associativa dos conteúdos evocados pela pessoa em relação a estímulos indutores, e realça os conteúdos encobertos, salientes e não filtrados pela censura (Nóbrega \& Coutinho, 2003). Para a aplicação da TALP, nesta pesquisa, foram utilizados três estímulos-indutores: "depressão", "ser mãe" e "ter filho(a)", coletados individualmente entre as participantes, com uma ordem aleatória de apresentação.

O questionário sociodemográfico continha questões sobre a idade da mãe, tempo de puerpério, tipo do parto, número de filhos, religião, ocupação, estado civil, renda familiar e escolaridade.

A escala de Edinburgh (Santos, Martins, \& Pasquali, 1999) é um instrumento para rastreamento da depressão pós-parto, desenvolvido na Grã-Bretanha (Edinburgh postnatal depression scale - EPDS) e validado no Brasil. O estudo brasileiro alcançou 0,80 de consistência interna, medida pelo alfa de 
Crombach. Essa escala também foi validada para o Nordeste no estudo de Cantilino et al. (2003), e consiste em um instrumento composto de dez enunciados, cujas opções são pontuadas entre 0 e 3 , de acordo com a presença ou intensidade do sintoma. Seus itens abordam sintomas da depressão pós-parto, tais como: humor deprimido ou disfórico, distúrbio do sono, perda do prazer, idéias de morte e de suicídio, diminuição do desempenho e culpa.

\section{Procedimentos}

Após a assinatura do termo de consentimento livre e esclarecido, foram aplicados individualmente às participantes os instrumentos da pesquisa na seguinte ordem: TALP, questionário e escala de Edinburgh. As respostas das mães foram anotadas pelo pesquisador, tendo em vista que as participantes, durante a aplicação dos instrumentos, conduziam no colo os seus bebês recém-nascidos.

Em seguida à aplicação dos instrumentos, os dados da escala de Edinburgh e o questionário foram processados pelo programa estatístico SPSS, versão 13.0.

Para o TALP, as respostas das participantes aos três estímulos-indutores foram processadas por meio do programa computacional TriDeux-Mot, versão 2.2 (Cibois, 1998).

O Tri-Deux-Mot possibilita a representação gráfica da atração e do distanciamento obtidos entre as variáveis fixas, identificadas pelo questionário sociodemográfico, e as variáveis de opinião, obtidas pelas respostas das participantes aos três estímulos indutores do Teste de Associação Livre de Palavras. Esse programa computacional, de acordo com Oliveira e Amâncio (2005), revela-se bastante apropriado para o tratamento de questões abertas, fechadas e associação livre de palavras, que foram analisadas por meio da análise fatorial de correspondência (AFC).

A interpretação da AFC permite ao pesquisador apreender os aspectos processuais e dimensionais relacionados ao estudo das representações sociais, motivo pelo qual é identificada a sua pertinência neste estudo sobre a depressão puerperal no contexto da experiência materna.

O princípio básico da AFC consiste em destacar eixos que explicam as modalidades de respostas e mostram os elementos do campo representacional, ou seja, os conteúdos a serem apreendidos nos discursos das mulheres puérperas frente aos estímulos indutores, com relação aos indicadores sociodemográficos mais evidentes.

\section{Resultados e discussão}

\section{Caracterização das participantes}

De acordo com as respostas ao questionário sociodemográfico, as sessenta e cinco participantes possuíam idades que variavam entre 18 e 38 anos $(X=27,5$ anos, DP $=$ $5,88)$, o período de puerpério observado foi entre 15 a 90 dias $(X=40,5$ dias, DP $=20,44)$, a grande maioria, ou seja, $76 \%$, teve parto vaginal ou normal, $63 \%$ das participantes tinham apenas um filho, sendo que $48 \%$ não são casadas civilmente e residem com seus companheiros. A maioria das mães estudadas (43\%) possui o ensino fundamental incompleto, informou que sua religião é católica (54\%), um percentual de $42 \%$ indicou que a renda familiar por pessoa está na faixa entre $R \$ 61,00$ e $R \$ 120,00$, e $49 \%$ das participantes responderam não ter ocupação fora de casa. 
Observa-se, pelos dados apresentados, que a maioria das participantes deste estudo possuíam um perfil sociodemográfico denotativo de baixa escolaridade, de renda familiar situada na linha de extrema carência financeira, de pouca inserção no mercado de trabalho formal, além de um vínculo informal de união matrimonial.

\section{Escala de Edinburgh}

Levando em consideração o registro de pontuações válidas, entre 1 e 3 pontos obtidos para cada um dos dez itens da escala de Edinburgh, a seguir, serão apresentados os resultados percentuais para cada grupo de mães, com e sem sintomatologia da depressão pós-parto.

As 32 participantes com sintomatologia de depressão pós-parto apresentaram pontuações que variavam entre 11 e 21 pontos ( $X=15,41$ e $D P=2,75)$ na escala de Edinburgh. As trinta e três mães sem sintomatologia depressiva obtiveram entre $0 \mathrm{e}$ 9 pontos na escala $(X=6,30$ e $\mathrm{DP}=1,61)$.

Observou-se que, para o item 2 da escala de Edinburgh, sobre sintoma de perda de prazer, $59 \%$ das mães com sintomatologia obtiveram pontuações válidas, enquanto apenas 12,3\% das mães sem sintomatologia obtiveram entre 1 e 3 pontos. Quanto às respostas ao item 3, que aborda o sentimento de culpa, $29,2 \%$ das mães deprimidas fizeram entre 1 e 3 pontos, enquanto apenas $10,7 \%$ das mães do outro grupo apresentaram pontuação válida.

Para as respostas ao item 7 da escala de rastreamento da depressão pós-parto, sobre distúrbio do sono, foram registradas as pontuações entre 1 e 3 em $42,3 \%$ das mães deprimidas e em 3,1\% das mães sem sintomatologia depressiva. Entre as mães com sintomatologia, foi observado que $46,2 \%$ destas fizeram entre 1 e 3 pontos no item 8, que aborda sintomas de humor deprimido. No caso das mães sem sitomatologia, esse índice ficou em 3,1\%.

No item 9, que trata de humor deprimido, combinado com a manifestação de choro, $47,7 \%$ das mães deprimidas obtiveram pontuação positiva na escala de Edinburgh, enquanto, no caso das mães sem sintomatologia, esse percentual ficou em $18,5 \%$

Em relação ao item 10, que trata de idéias de morte e de suicídio, nenhuma mãe do grupo sem sintomatologia da depressão pósparto apresentou pontuação positiva nesse item. Enquanto isso, há o registro de 37,5\% de mães com sintomatologia da depressão puerperal que fizeram entre 1 e 3 pontos para esse item.

Para os demais itens da escala de Edinburgh, os dois grupos de mães não apresentaram pontuações diferenciadas que merecessem uma análise mais detalhada; portanto, de acordo com as respostas das participantes aos itens da escala de rastreamento da depressão puerperal, pode-se inferir que os elementos sintomatológicos mais expressivos identificados nas mães deprimidas concentraram-se naqueles denotativos da perda de prazer diante das atividades rotineiras, sentimento de culpa sem motivo aparente, distúrbios do sono e humor deprimido com a manifestação de choro, além de apreensão de ideação suicida.

\section{Análise dos dados pelo Tri-Deux-Mot}

As análises das evocações coletadas a partir dos dados obtidos no Teste de Associação Livre de Palavras foram processadas pelo Tri-Deux-Mot, levando em consideração as 
evocações das mães aos três estímulos-indutores e às variáveis sociodemográficas: idade das mães, tempo de puerpério e presença ou ausência de sintomatologia da depressão puerperal.

A técnica de associação livre de palavras aplicada a esta pesquisa possibilitou, a partir do processamento pela AFC, o registro de 954 palavras como respostas aos estímulos indutores: "depressão", "ser mãe" e "ter filho(a)". Dessas palavras, 353 foram diferentes, reduzidas de acordo com a junção dos termos com similaridade semântica.

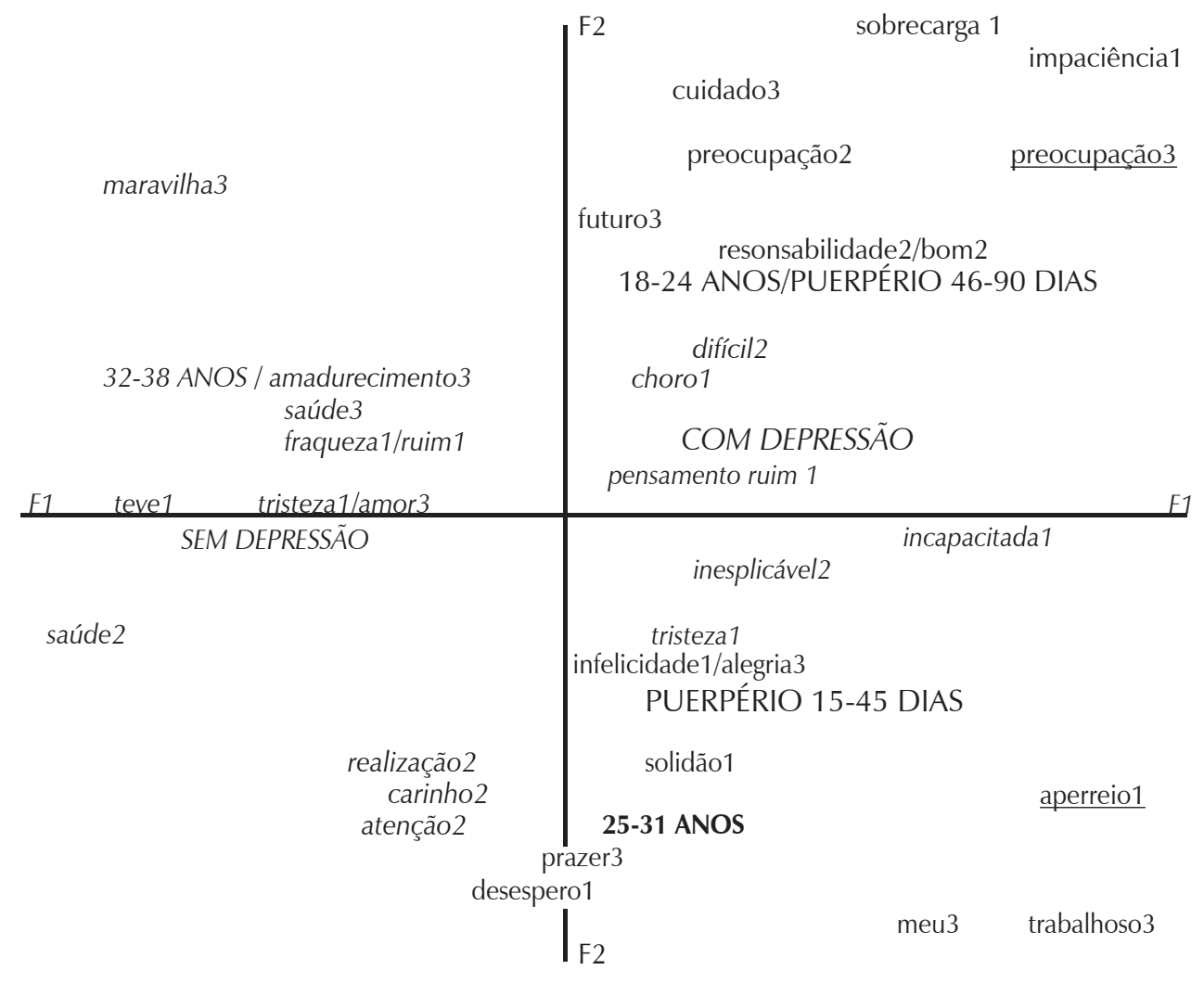

Figura 1. Plano fatorial de correspondência das representações sociais elaboradas pelas mães puérperas.

Legenda do Plano Fatorial:

Fator 1 (F1) em itálico, localiza-se no eixo horizontal à direita e à esquerda. Fator 2 (F2), em negrito, localiza-se no eixo vertical superior e inferior.

Variáveis de opinião ou estímulos indutores. O número no final de cada palavra significa: 1 = depressão; 2 = ser mãe; 3 = ter filho(a). As palavras pertencentes a dois campos semânticos encontram-se sublinhadas.

Variáveis fixas (em caixa alta): depressão pós-parto: com e sem depressão; faixas de idade da mãe: 18-24 anos, 25-31 anos, 32-38 anos; períodos de puerpério: 15-45 dias e 46-90 dias. 
Para esse grupo, depressão é sinônimo de tristeza e fraqueza.
A análise da Figura 1 foi feita a partir da leitura das modalidades, as palavras evocadas ou os campos semânticos, distribuídos de maneira oposta nos dois eixos ou fatores (F1 e F2). Os dois fatores juntos explicam $64,9 \%$ da variância total das respostas e focalizam, especificamente, a análise das variáveis ou modalidades que tiveram contribuição superior a duas vezes a média das cargas fatoriais identificadas no programa computacional.

De acordo com a Figura 1, o primeiro fator (F1), na linha horizontal, revela as maiores cargas fatoriais, especificamente, aquelas evocações correspondentes, provavelmente, às representações sociais apreendidas. Esse fator explica $43,7 \%$ da variância total de respostas das participantes.

Para o primeiro fator, destacam-se, no lado negativo ou à esquerda da Figura 1, as evocações que emergiram das mães sem sintomatologia da depressão e com idades entre 32 e 38 anos. Por oposição, no mesmo eixo ou fator 1 , no lado positivo, à direita, salientam-se as objetivações das mães com sintomatologia de depressão pós-parto.

Com relação ao segundo fator (F2), na linha vertical da Figura 1, destacam-se dois agrupamentos de evocações com as maiores cargas fatoriais, que explicam $21,2 \%$ da variância total de respostas das participantes.

Para o Fator 2, emergiram dois campos semânticos: um, no plano superior, manifestado pelas mães com idades entre 18 e 24 anos e que se encontravam entre quarenta e seis e noventa dias de puerpério, e, por contraste e oposição, no plano inferior, emergem evocações das mães com idades que variam entre 24 e 31 anos, com bebês entre quinze e quarenta e cinco dias de nascidos.
A seguir, estão apresentadas as interpretações das representações sociais das mães puérperas acerca da depressão no contexto da experiência materna.

\section{Abordagem processual das representações sociais acerca da depressão}

Observando a Figura 1, no eixo à esquerda, encontra-se agrupado o campo semântico da representação sobre a depressão pósparto e a experiência materna, conforme caracterizaram as participantes com idades entre 32 e 38 anos, sem sintomatologia da depressão.

Para esse grupo, depressão é sinônimo de tristeza e fraqueza. Emerge, ainda, a identificação de mães puérperas que revelam que, em tempos anteriores, tiveram depressão e, por isso, avaliaram esse transtorno psico-afetivo como ruim. Esses elementos apreendidos no TALP parecem denotar que essas mães ancoram a depressão em manifestações psico-orgânicas (fraqueza), psico-afetivas, valorativas e histórico-temporais.

Com respeito à expressão fraqueza, chamam a atenção os dois sentidos possíveis para significar o ser fraco. Por um lado, percebe-se um estado de qualidade de fraco enquanto falta de força, de vigor, de solidez ou energia, debilidade, fragilidade, desânimo e desalento, fraqueza, portanto, enquanto manifestação predominantemente orgânica. De outro lado, pode significar uma avaliação negativa na direção de uma falha ou defeito, como covardia, falta de obstinação, ou seja, o lado fraco de um caráter de um ser, o que revela uma propensão para ceder a sugestões, imposições ou impressões, fraqueza, dessa feita, enquanto manifestação psicológica. Essas duas esferas da representação social 
da depressão, enquanto elemento fraqueza, são corroboradas pelas manifestações valorativa (é ruim) e histórico-temporal (já tive depressão).

Destaca-se na Figura 1, ainda, o bloco de representações estabelecidas em oposição ao fator 1, eixo à direita, das puérperas com sintomatologia da depressão, que caracterizam a depressão como tristeza e aperreio, manifestados pelo choro, impaciência e pensamentos ruins, condições que as incapacitam para suas atividades maternas. Observa-se a utilização por esse grupo da expressão aperreio, que traduz manifestação lingüística adotada do Nordeste do Brasil, de acordo com Ferreira (1999), aglutinadora de sentimentos de opressão, apertura ou dificuldades.

Essas mães deprimidas, diferentemente das puérperas sem sintomatologia depressiva, ancoram a depressão em manifestações cognitivo-comportamentais, e realçam os pensamentos negativos em relação a si mesmas e aos seus bebês, provavelmente na direção de idéias de morte e ideação suicida.

Diante dos campos semânticos atraídos pelo Fator 1, para ambos os grupos de puérperas, com e sem sintomatologia da depressão, observa-se a presença da representação social da depressão ancorada na concepção erudita descrita e divulgada pela nosologia psiquiátrica, que agrupa os elementos sintomatológicos em torno da tristeza. Isso denota que esse conhecimento científico foi utilizado e selecionado pelas participantes a partir da sua experiência subjetiva e da sua inserção social, o que as levou a construir sua teoria do senso-comum sobre a depressão.

Considerando a interpretação das evocações que emergem no fator 2, eixo vertical, para os três estímulos-indutores, configuram-se, de um lado, as representações sociais das participantes quanto à faixa etária entre 18 e 24 anos, as mais novas da amostra, com bebês entre quarenta e seis e noventa dias de nascidos. Por outro lado, diametricamente distanciadas, no plano inferior, emergem evocações das mães que têm entre 24 e 34 anos de idade, na fase do puerpério tardio, entre quinze e quarenta e cinco dias. Isso pode evidenciar as discordâncias representacionais entre esses dois grupos de mães.

O plano superior da Figura 1 destaca o grupo de mães mais novas, incluídas na fase do puerpério remoto, que representa a depressão enquanto sobrecarga, que lhes provoca impaciência, com o uso de expressões que se ancoram em elementos cognitivocomportamentais.

Por contraste, no plano inferior do Fator 2, o grupo de mães com idades entre 25 e 31 anos, que vivenciavam o puerpério tardio (entre 15 e 45 dias), representa a depressão, por sua vez, como aperreio, desespero, infelicidade e solidão, expressões ancoradas nas manifestações psico-afetivas. Mais uma vez, emerge no campo semântico das participantes a expressão nordestina aperreio, já registrada entre as objetivações das mães deprimidas acerca da depressão.

\section{Abordagem processual das representações sociais da experiência materna}

Esta análise será efetuada concomitantemente para os dois estímulos-indutores "ser mãe" e "ter filho(a)", uma vez que foi freqüente a intersecção de expressões entre eles, possivelmente pela simbiose revelada pela díade mãe-filho, diante da recente experiência materna nas fases de puerpério tardio e remoto. 
As mães com sintomatologia da depressão pósparto representam sua experiência materna ancoradas em valores negativos, como: "ser mãe é difícil", acompanhados de uma expressão lingüística possivelmente reveladora de embotamento afetivo - "ser mãe é inexplicável".
Para participantes com idades entre 32 e 38 anos, as mais velhas da amostra estudada e sem sintomatologia da depressão, a experiência de ser mãe aglutinou, no plano esquerdo da Figura 1, o campo semântico com as manifestações afetivas positivas, carinho, atenção, saúde, dirigidas ao filho, que lhes proporcionava realização como mães. O campo semântico observado pelas objetivações das mães sem sintomatologia depressiva difere das manifestações negativas assinaladas no lado direito do plano fatorial (Fator 1).

As mães com sintomatologia da depressão pós-parto representam sua experiência materna ancoradas em valores negativos, como: "ser mãe é difícil", acompanhados de uma expressão lingüística possivelmente reveladora de embotamento afetivo "ser mãe é inexplicável". Por sua vez, a representação social de estímulo-indutor ter filho, para essas mães, encontra-se ancorada em manifestações cognitivocomportamentais, ocasião em que emerge a expressão preocupação.

Por oposição, as mães sem sintomatologia da depressão, assim como nas representações acerca de "ser mãe", dessa feita para o estímulo "ter filho(a)", ancoram suas representações em manifestações afetivas positivas, como maravilha, com atenção para a saúde do bebê, que, além de realizá-las enquanto pessoas, Ihes traz amadurecimento.

Ressalte-se que o grupo de puérperas sem sintomatologia depressiva que emergiu no campo representacional do eixo horizontal à esquerda possui as maiores idades entre as mães pesquisadas - entre 32 e 38 anos. Nesse caso, o elemento amadurecimento está ancorado nas manifestações histórico-factuais, igualmente presentes na ancoragem das representações sociais acerca da depressão desse grupo de pertencimento. No caso das representações sociais da depressão e da experiência materna, portanto, a história de vida parece um elemento importante na construção e elaboração social dessas mulheres.

Chama a atenção, nesse contexto, a oposição entre as manifestações cognitivas que ancoram as representações sociais de "ter filho(a)" entre as mães deprimidas e as manifestações histórico-factuais que embasam essas representações das puérperas sem sintomatologia. A experiência e a história de vida das puérperas sinalizam contribuições diferentes na construção do senso comum sobre as conseqüências da maternidade.

O plano superior da Figura 1 destaca o grupo de mães mais novas, entre 18 e 24 anos, incluídas na fase do puerpério remoto. Ser mãe para elas está ancorado em elementos afetivos positivos - é bom ser mãe - embora Ihes exija apresentar atitudes e pensamentos de maior responsabilidade do que em fases anteriores de sua vida, fato que, diante das mudanças advindas da chegada do seu bebê, Ihes traz preocupação. Essa manifestação cognitivo-comportamental também foi registrada entre as expressões colhidas a partir do estímulo "ter filho(a)", preocupação essa, dessa feita, claramente voltada para o futuro do filho. Por se tratar neste estudo de puérperas de baixa renda, pode-se inferir que as preocupações com o futuro dos filhos se concentram nas atuais dificuldades financeiras em mantê-los sob a sua responsabilidade.

Por contraste, no plano inferior do Fator 2, o grupo de mães com idades entre 25 e 31 anos, com bebês entre quinze e quarenta e cinco dias de nascidos, não apresentou evocação que aglutinasse cargas fatoriais expressivas e consensuais, motivo pelo qual não emergiram as representações sociais sobre 
a experiência materna. Por sua vez, essas mães representaram o estímulo "ter filho(a)" nas expressões alegria e prazer, acompanhadas de evocações de que o bebê dá muito trabalho. Para essas participantes, observa-se a objetivação da representação social de "ter filho(a)" enquanto meu filho, expressão do seu poder sobre o filho, na relação simbiótica entre possuidor e possuído. O emprego da expressão é meu poderá revelar "aquele bebê que me é devido; que me cabe ou me toca, assim como o bebê caro a mim, querido por mim".

Esse campo semântico que relaciona a expressão o bebê é meu à evocação trabalhoso poderá significar a concentração da responsabilidade exclusivamente na própria mãe sobre o filho recém-nascido, o que denota, provavelmente, a ausência ou insuficiência de suporte familiar nesse momento de puerpério.

\section{Considerações gerais}

Com o objetivo de apreender e descrever as representações sociais da depressão pós-parto, tomando como referência um conhecimento elaborado e compartilhado socialmente por mães puérperas usuárias de um serviço público de saúde, foi possível destacar eixos que explicam as modalidades de respostas ou as evocações das puérperas e que mostram estruturas constituídas de elementos do campo representacional, semântico ou gráfico.

Houve o registro da atração e oposição das variáveis sociodemográficas pesquisadas, principalmente com o surgimento do campo semântico das mães com e sem sintomatologia da depressão puerperal, assim como um destaque para as faixas etárias e o tempo de puerpério das participantes. Ressaltese, desse modo, que o agrupamento das evocações das participantes frente às variáveis estudadas poderá revelar representações sociais ancoradas em elementos diferentes para cada grupo de pertença.

Comparado com as manifestações registradas nas falas das puérperas sem sintomatologia depressiva, o campo semântico que emergiu das mães com sintomatologia de depressão aglutina poucos elementos com altas cargas fatoriais, isto é, para representar a depressão, as mães deprimidas tiveram dificuldades em emitir palavras para expressar esse transtorno psico-afetivo. Tal fato pode sinalizar a necessidade de maior aprofundamento da investigação, através, por exemplo, de uma entrevista em profundidade, ocasião em que, provavelmente, estarão evidenciadas as razões para esse provável embotamento lingüístico.

O contexto relacionado à maternidade, pesquisado a partir dos estímulos "ser mãe" e "ter filho(a)", por sua vez, possibilitou a compreensão das representações sociais da experiência materna enquanto vivência exclusivamente feminina, a partir de suas elaborações cognitivas e afetivas, percepções e experiências de vida compartilhadas por crenças, atitudes, valores e informações, objetivadas por meio de elementos ancorados nos sistemas psico-orgânicos do puerpério e no contexto social nos quais as participantes se encontram inseridas.

As representações sociais elaboradas pelas participantes desta investigação, independentemente da presença ou ausência de sintomatologia depressiva, denotaram uma aproximação com a concepção de depressão descrita tradicionalmente pela nosologia psiquiátrica, o que revela um agrupamento de elementos sintomatológicos em torno da tristeza, manifestação psico-afetiva também presente nos estudos sobre a depressão 
A primeira

complementação

deste estudo

poderá ser

concretizada pela

análise estrutural

das representações

sociais das

participantes, de

modo a levantar

hipóteses sobre o

seu núcleo central,

da zona muda

e do seu sistema periférico. em crianças, adolescentes, adultos jovens, idosos e soropositivos (Castanha, Coutinho, Saldanha, \& Ribeiro, 2006; Coutinho, 2005; Coutinho \& Saldanha, 2005; Coutinho, Gontiés, Araújo, \& Sá, 2003).

A ocorrência da depressão pós-parto registrada na amostra estudada, de usuárias de um serviço público de saúde que, durante a coleta dos dados, não buscavam atendimento para si próprias, mas tão somente para consulta dos filhos recém-nascidos, reforça a necessidade de uma urgente atenção e intervenção dos profissionais da saúde na direção de maior visibilidade para as dificuldades maternas, que se escondem por trás da procura do atendimento exclusivamente para seus bebês. As ações dirigidas às puérperas poderão ser efetivadas por uma equipe multidisciplinar de saúde, concentrandose em medidas preventivas dirigidas, por exemplo, à aplicação rotineira da escala de Edinburgh para rastreamento da depressão materna e ao acolhimento dessas mulheres no ambiente coletivo da sala de espera. As conseqüências dessas ações poderão resultar em atendimentos psicoterapêuticos individuais e grupais assim como em palestras e orientações educativas voltadas para as temáticas de interesse das mães que vivenciam o período puerperal.
Dessa maneira, a visibilidade do sofrimento após o parto, assim como a tomada de decisão sobre as intervenções pertinentes, poderão prevenir graves problemas pessoais e familiares decorrentes desse tipo de transtorno bio-psíquico-afetivo (Brum \& Schermann, 2006; Frizzo \& Piccinini, 2005; Schwengber \& Piccinini, 2003).

Os resultados relatados neste estudo não são conclusivos, já que é evidente a importância e a necessidade de adotar um arsenal plurimetodológico para melhor apreender o complexo fenômeno das representações sociais. Para tanto, faz falta a este estudo a sua complementação por meio de, no mínimo, duas direções não excludentes entre si. A primeira complementação deste estudo poderá ser concretizada pela análise estrutural das representações sociais das participantes, de modo a levantar hipóteses sobre o seu núcleo central, da zona muda e do seu sistema periférico. A outra direção possível poderia ser a continuação deste estudo por meio da escuta, registro, análise e inferências a respeito do conteúdo lingüístico das participantes, quer obtidos individualmente pela entrevista em profundidade quer por meio de discussões em grupos de pertença, com a utilização, por exemplo, da técnica de grupos focais. 


\section{Maria da Penha de Lima Coutinho}

Departamento de Psicologia da Universidade Federal da Paraíba (UFPB)

Doutora em Psicologia pela Universidade de São Paulo (USP) e Pós-Doutora pela Universidade Aberta de LisboaPortugal

E-mail: penhalcoutinho@yahoo.com.br

\section{Evelyn Rúbia de Albuquerque Saraiva}

Departamento de Psicologia da Universidade Federal da Paraíba (UFPB)

Especialista em Psicologia da Educação pela Pontifícia Católica de São Paulo (PUC/SP) e mestranda do Programa de Pós-Graduação em Psicologia Social da Universidade Federal da Paraíba

E-mail: evelynsaraiva@hotmail.com

Endereço para correspondência:

Rua Gláucia Maria dos Santos Gouveia, 418 - Manaíra Cep: 58038-640, João Pessoa - PB

Recebido 21/04/2007 Reformulado 06/06/2007 Aprovado 16/06/2007

\section{Referências}

Abou-Saleh, M. T., \& Ghubash, R. (1997). The prevalence of early postpartum psychiatric morbidity in Dubai: A transcultural perspective. Acta Psychiatrica Scandinavica, 95(5), 428-432.

Arrais, A. R. (2005). As configurações subjetivas da depressão pós-parto: para além da padronização patologizante. Tese de Doutorado, Universidade de Brasília, Brasília, DF. Recuperado em 22 de outubro de 2006, de http://www.unb.br/ip/web/pos/ res_d_2005.htm\#Alessandra\%20da\%20Rocha\%20Arrais
Arruda, A. (2002). A teoria das representações sociais e teorias de gênero. Cadernos de Pesquisa, 117, 127-147.

Banchs, M. A. (1998). Aproximaciones procesuales e estructurales al estudio de las representaciones sociales. Papers on Social Representations. Textes sur les Représentations Sociales, 9, 3.1-3.15.

Bolguese, M. S. (2004). Depressão e doença nervosa moderna. São Paulo: Via Lettera; Fapesp. 
Boyce, P. M., Johnstone, S. J., Hickey, A. R., Morris-Yates, A. D., Harris, M. G., \& Strachan, T. (2000). Functioning and well-being at 24 weeks postpartum of women with postnatal depression. Archives of Women's Mental Health, 3(3), 91-97.

Brum, E. H. M., \& Schermann, L. (2006). O impacto da depressão materna nas interações iniciais. Psico, 37(2), 151-158.

Cantilino, A., Albuquerque, C., Cantilino, G., Maia, A., \& Sougey, E. (2003). Validação da escala de depressão pósparto de Edinburgh (versão em português) no Nordeste do Brasil. Trabalho apresentado no XXI Congresso Brasileiro de Psiquiatria, Goiânia.

Castanha, A. R., Coutinho, M. P. L., Saldanha, A. A. W. \& Ribeiro, C. G. (2006). Repercussões psicossociais da depressão no contexto da AIDS. Psicologia: Ciência e Profissão, 26(1), 70-81.

Cibois, P. (1998). L'analyse factorielle (Colleccion "Que saisje?"). Paris: PUF.

Chandran, M., Tharyan, P., Muliyil, J., \& Abraham, S. (2002). Post-partum depression in a cohort of women from a rural area of Tamil Nadu, India: Incidence and risk factors. The British Journal of Psychiatry, 181(6), 499-504.

Conselho Nacional de Saúde. Ministério da Saúde. (1996). Resolução CNS no 196, de 10 de outubro de 1996. Aprova as diretrizes e normas regulamentadoras de pesquisas envolvendo seres humanos. Recuperado em 24 de novembro de 2005 de, http://conselho.saude.gov.br/docs/Resolucoes/Reso196.doc

Coutinho, M P. L. (2005). Depressão infantil e representação social (2a ed.). João Pessoa: Ed. Universitária UFPB.

Coutinho, M. P. L., \& Saldanha, A. A. W. (2005). Desenvolvimento sociohistórico da depressão e representações sociais. In M P. L. Coutinho \& A. A. W. Saldanha (Orgs.), Representações sociais e práticas de pesquisa (pp. 11-37). João Pessoa: Ed. Universitária UFPB.

Coutinho, M. P. L., Gontiés, B., Araújo, L. F., \& Sá, R. C. N. (2003). Depressão, um sofrimento sem fronteira: representações sociais entre crianças e idosos. Psico-USF, 8(2), 183-192.

Cruz, E. B. S., Simões, G. L., \& Faisal-Cury, A. (2005) Rastreamento da depressão pós-parto em mulheres atendidas pelo Programa de Saúde da Família. Revista Brasileira de Ginecologia e Obstetrícia , 27(4), 181-188.

Da-Silva, V. A., Moraes-Santos, A. R., Carvalho, M .S., Martins, M. L. P., \& Teixeira, N. A. (1998). Prenatal and postnatal depression among low income Brazilian women. Brazilian Journal of Medical and Biological Research, 31(6), 799-804.

Di Giacomo, J. P. (1981). Aspects méthodologiques de l'analyse des réprésentations sociales. Cahiers de Psychologie Cognitive, 1, 397-422.

Farr, R. M. (1994). Representações sociais: a teoria e sua história. In P. Guareschi \& S. Jovchelovtih (Orgs), Textos em representações sociais (pp. 31-55). Petrópolis, RJ: Vozes.

Ferreira, A. B. H. (1999). Dicionário Aurélio eletrônico - Século XXI [versão 3.0].

Frizzo, G. B., \& Piccinini, C. A. (2005). Interação mãe-bebê em contexto de depressão materna: aspectos teóricos e empíricos. Psicologia em Estudo, 10(1), 47-55.

Howard, L. (2005). Posnatal depression. Recuperado em 3 de maio de 2006, de http://www.clinicalevidence.com/ceweb/ conditionpdf/1407.pdf
Howell, E. A., Mora, P. M., \& Leventhal, H. (2006). Correlates of early postpartum depressive symptoms. Maternal and Child Health Journal, 10(2), 149-157.

Inandi T., Elci, O. C., Ozturk A., Egri, M., Polat, A., \& Sahin, T. K. (2002). Risk factors for depression in postnatal first year in eastern Turkey. International Journal of Epidemiology, 31(6), 1201-1207.

Jodelet, D. (2001). Representações sociais: um domínio em expansão. In D. Jodelet (Org.), As representações sociais (pp. 17-41). Rio de Janeiro: Ed. UERJ.

Kaplan, H. I., \& Sadock, B. J. (1990). Compêndio de psiquiatria (2a ed.). Porto Alegre: Artes Médicas.

Kyes, J. J., \& Hofling, C. K. (1985). Conceitos básicos em enfermagem psiquiátrica (4a ed.). Rio de Janeiro: Interamericana.

Kuo, W-H, Wilson, T. E., Holman, S., Fuentes-Afflich, E., O'Sullivan, M. J., \& Minkoff, H. (2004). Depressive simpthoms in the immediate postpartum period among Hispanic women in three U. S. Cities. Journal of Immigrant Health, 6(4), 145153.

Lara, M. A., Acevedo, M., \& Berenzon, S. (2004). La depresión feminina vista desde la subjetividad de las mujeres. Cadernos de Saúde Pública, 20(3), 818-828.

Moreira, R., \& Lopes, R. L. (2006) Sexualidade e gravidez: aspectos da vida da mulher - revisão da literatura. Brazilian Journal of Nursing, 5(1). Recuperado em 23 de setembro de 2006, de http://www.uff.br/objnursing/viewarticle.php?id=250.

Moscovici, S. (1978). A representação social da psicanálise. Rio de Janeiro: Zahar.

Moscovici, S. (2003). Representações sociais: investigações em psicologia social (2a ed.). Petrópolis, RJ: Vozes.

Nóbrega, S. M., \& Coutinho, M. P. L. (2003). O teste de associação livre de palavras. In P. L. Coutinho (Org.), Representações sociais: abordagem interdisciplinar (pp. 67-77). João Pessoa: Ed. Universitária UFPB.

Nóbrega, S. M., Fontes, E. P. G., \& Paula, F. M. S. M. (2005). Do amor e da dor: representações sociais sobre o amor e o sofrimento psíquico. Estudos de Psicologia, Campinas, 22(1), 77-87.

Oliveira, A., \& Amâncio, L. (2005). A análise factorial de correspondência no estudo das representações sociais - as representações sociais da morte e do suicídio na adolescência. In A. S. P. Moreira, B. V. Camargo, J. C. Jesuíno, \& S. M. Nóbrega (Orgs.), Perspectivas teórico-metodológicas em representações sociais (pp. 323-362). João Pessoa: UFPB.

Santos, M. F. S., Martins, F. C., \& Pasquali, L. (1999). Escala de auto-avaliação de depressão pós-parto: estudo no Brasil. Revista de Psiquiatria Clínica, 26(2), 90-95. Edição especial.

Schwengber, D. D. S., \& Piccinini, C. A. (2003). O impacto da depressão pós-parto para a interação mãe-bebê. Estudos de Psicologia, 8(3), 403-411.

Sierra Manzano, J. M., Carro García, T., \& Ladrón, M. E. (2002). Variables associated with the risk of postpartum depression. (Edinburgh postnatal depression scale). Atención Primaria, 30(2), 103-11.

Silva, E. T., \& Botti, N. C. L. (2005). Depressão puerperal: uma revisão da literatura. Revista Eletrônica de Enfermagem, 7(2), 231-238. Recuperado em 9 de outubro de 2006, de http:// www.fen.ufg.br/revista/revista7 2/revisao_10.htm 